\title{
ANALYSIS OF VECTOR BORNE DISEASE USING UCINET
}

\author{
Badrinaathan. $\mathbf{J}^{1}, \mathrm{G}$ Vadivu $^{2}$
}

Abstract-The prevalence of vector borne diseases has been the major public health and challenging problems in more than 100 tropical countries and it has been affecting more than $\mathbf{5 0 \%}$ of the population in the world, especially in India. The vector borne diseases are caused by the agent called disease vector that carries and transmits an infectious pathogen into another living organism. The environmental conditions like land cover changes, climatic changes in those regions, urban agglomeration, industrial development also takes a major role in transmission of these diseases. Examples for vector borne diseases are malaria, filariasis, Plague, dengue and chikungunya. With the help of UCINET,path of the regions affected by vector borne diseases are identified and graphs are obtained. This study is been done by data pertaining to vector borne diseases were collected using the details obtained from the death rates of each state in India.

Keywords: vector borne disease, malaria, filariasis, dengue, chikungunya, UCINET.

\section{INTRODUCTION}

The burden of vector borne diseases in India has become very challenging problem and increasing day by day. The prevalence of geographical distribution of vector borne diseases has been increasingly public health important and challenging problems in more than 100 tropical countries and it has been affecting more than $50 \%$ of the population in the world, especially, it is big problem in India. The geographical distribution and seasonal variation of vector abundance and vector borne disease transmission have

completely been controlled by the climate, landscape and the environmental variables (land use / land cover, altitude, mean annual temperature, mean annual rainfall, readily available soil moisture, soil type's water logging potential, slope of the terrain. The present study is designed for mapping the spatial distribution of malaria, JE, filariasis, dengue, chikungunya. The information relevant to the vector borne diseases, and vector abundance in association with geo-climate determinant variables provides datum of guide lines to mapping of vertical and horizontal structure of the disease transmission risk and to assess the community of the people at risk in different parts of the country.

\section{LITERATURE REVIEW}

\section{EXISTING SYSTEM}

The study is designed for a systematic review on the spatial cognition of vector borne disease transmission and the environment, using satellite remote sensing and GIS, the has in-built with fulfilling the following four fold objectives:- 1. To mapping the spatial distribution of vector borne diseases in India. 2. To study the climate, landscape, and the environmental aspects of vector borne disease transmission in India. 3. To study the spatial agreements between the geo-environmental variables and vector borne disease transmission in India. 4. To analyses the spatial cognition: A geospatial modeling of geoenvironmental aspects of vector borne disease transmission in India, using remote sensing and GIS system.

\section{PROPOSED SYSTEM}

Mapping disease distribution and to assess the community of the people at risk in different parts of the country. The potential use of availability of health resource allocation, and hence, should be given priority when and where planning control campaigns, based on the disease transmission network focusing on individual districts or states. The result shows that the possible information on reliable estimates of and mapping of malaria and chikungunya vector breeding habitats, and facilitate to estimate the people at risk of vector borne disease transmission.

\footnotetext{
${ }^{1}$ SRM University, Katankulathur, Chennai, *Corresponding Author

${ }^{2}$ SRM University, Katankulathur, Chennai, *Corresponding Author
} 


\section{METHODOLOGY}

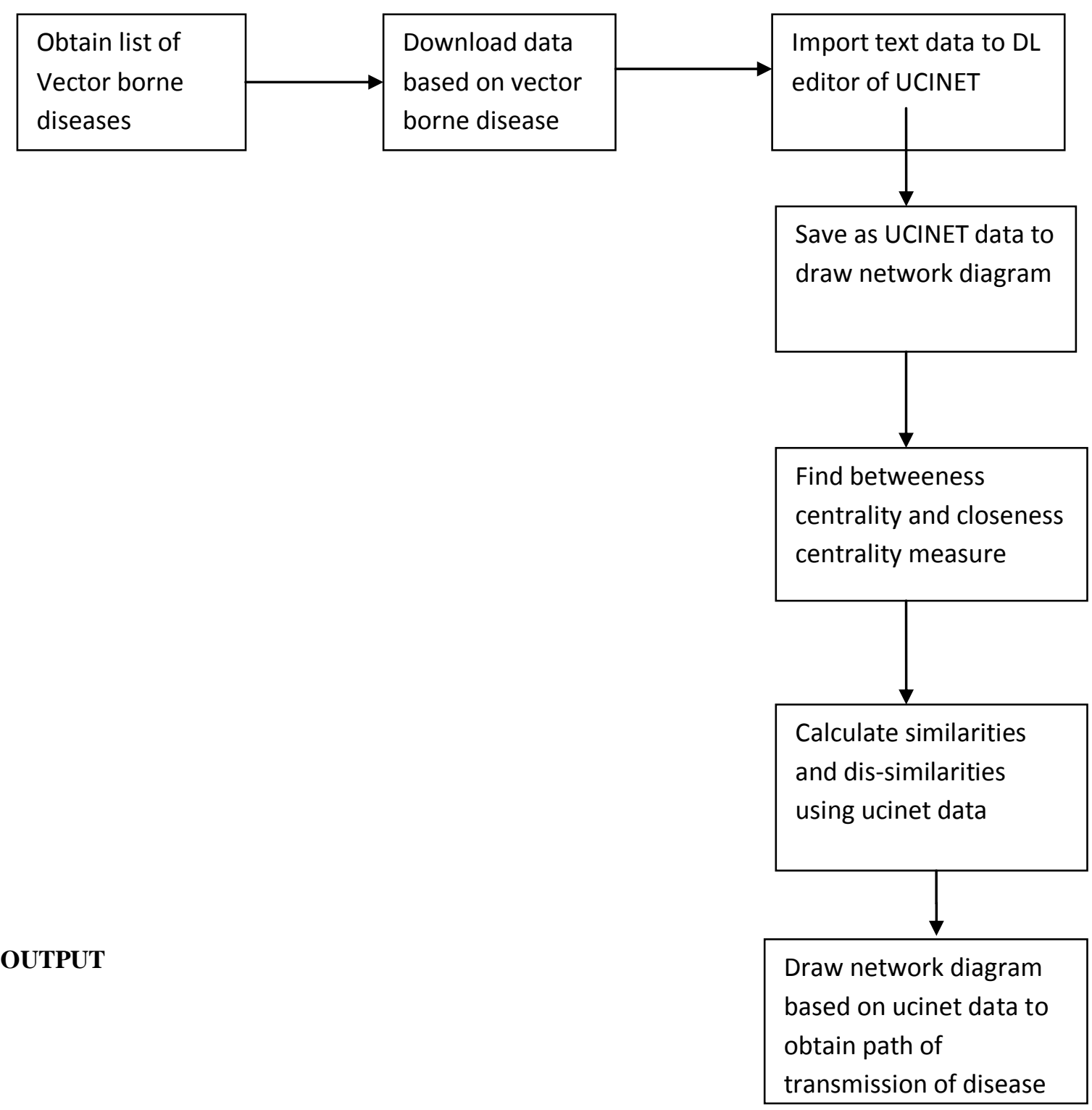

NETWORK DIAGRAMS

The below network diagram shows the disease caused by an individual vector. For example malaria, Chikungunya, Dengue fever, Yellow fever, etc are caused by the vector mosquito. 

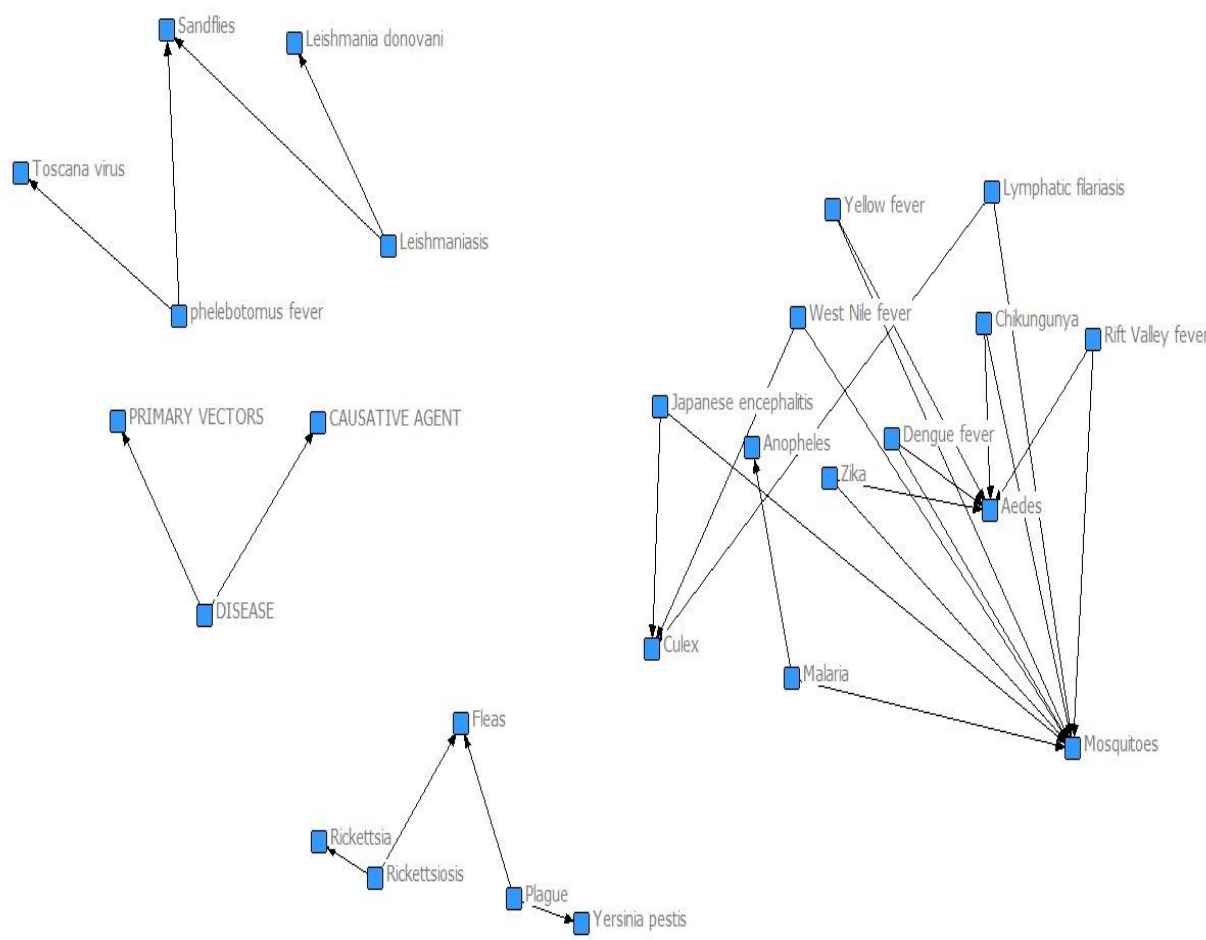

Fig 1: Disease Caused By An Individual Vector

The list of countries affected by malaria(vector borne disease) is shown below with the help of network diagram.
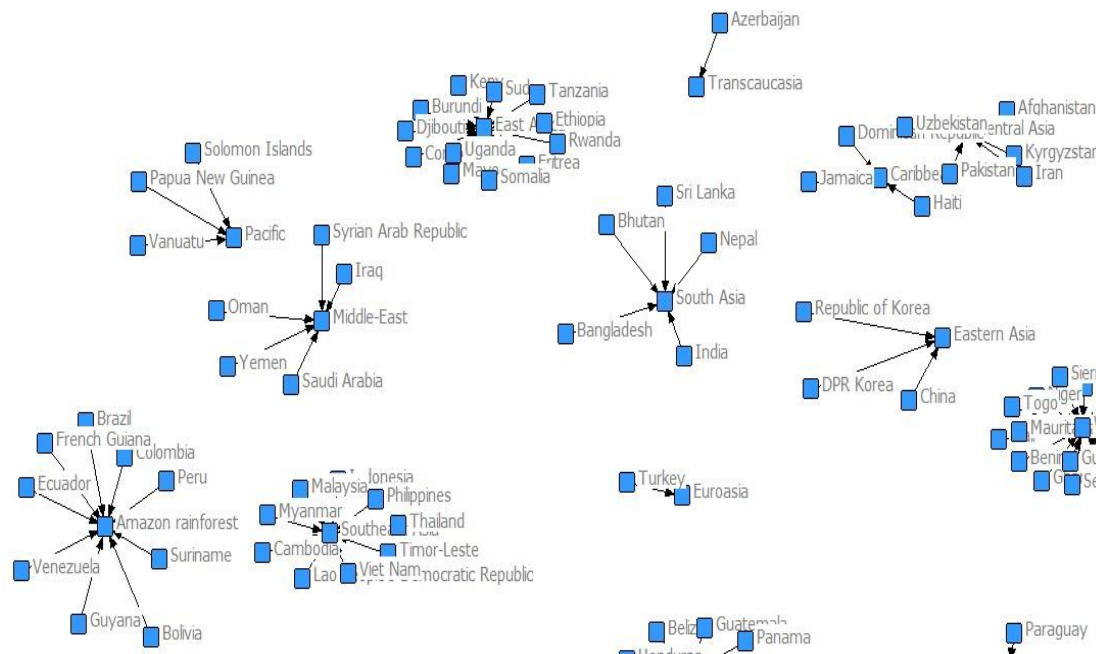

$\square$ Lao $\square$ Viet Nammocratic Republic
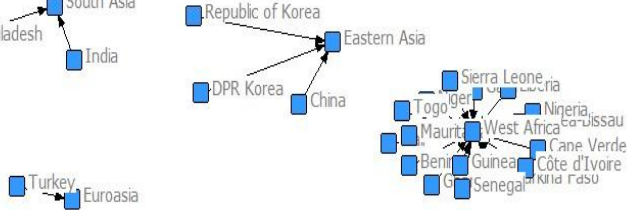

nzambia wazilanditus

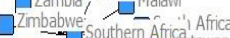

Mozanoule -7 intswan

$\square$ Nambián Madagascar

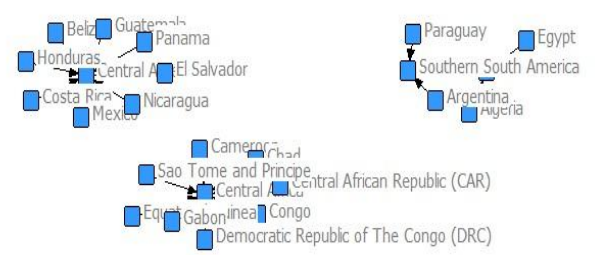

Fig 2: Countries Affected By Malaria 
The list of countries affected by chikungunya (vector borne disease) is shown below with the help of network diagram.
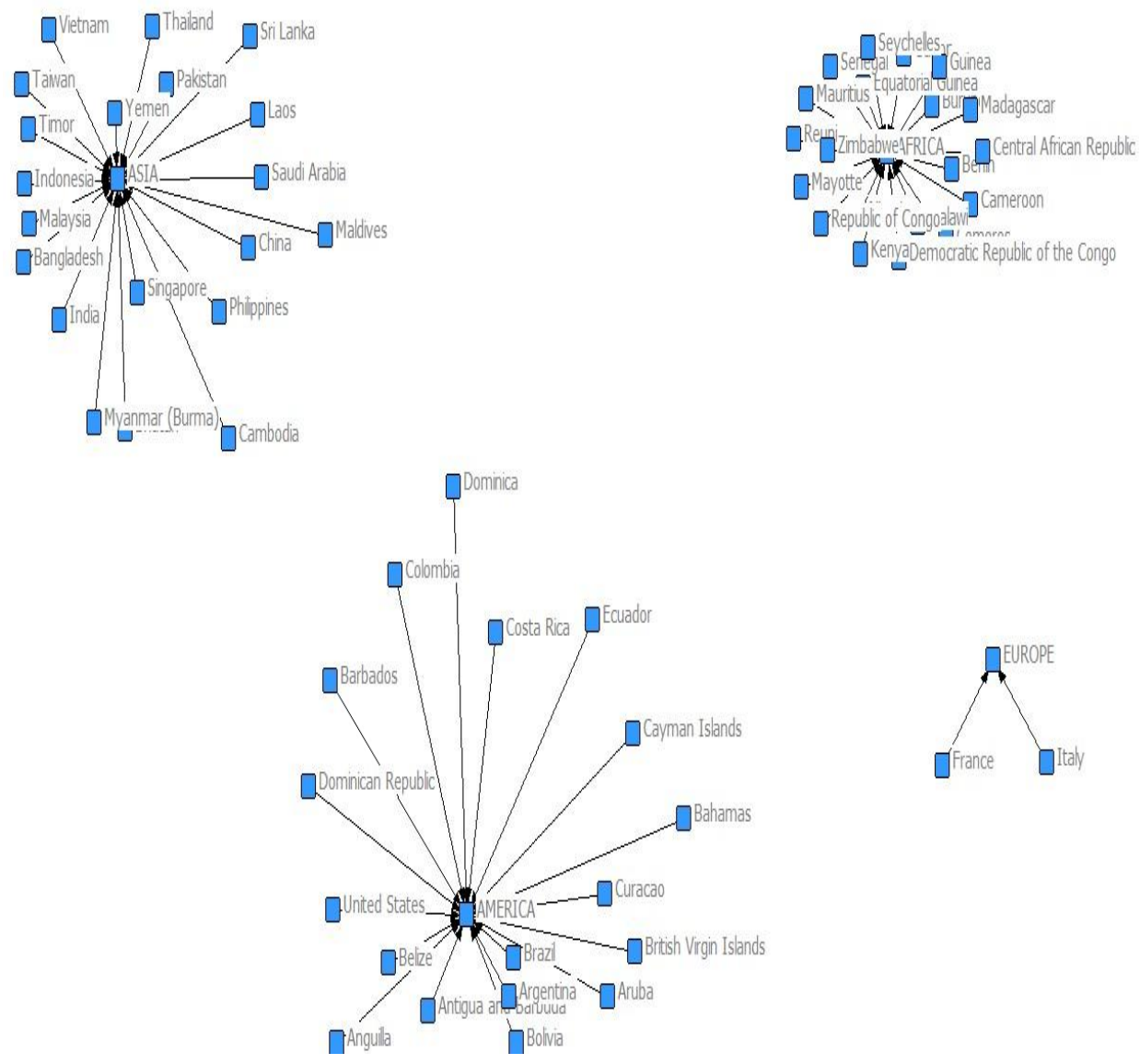

Fig 3: Countries Affected By Chikungunya

The network diagram given below shows the states affected by malaria.

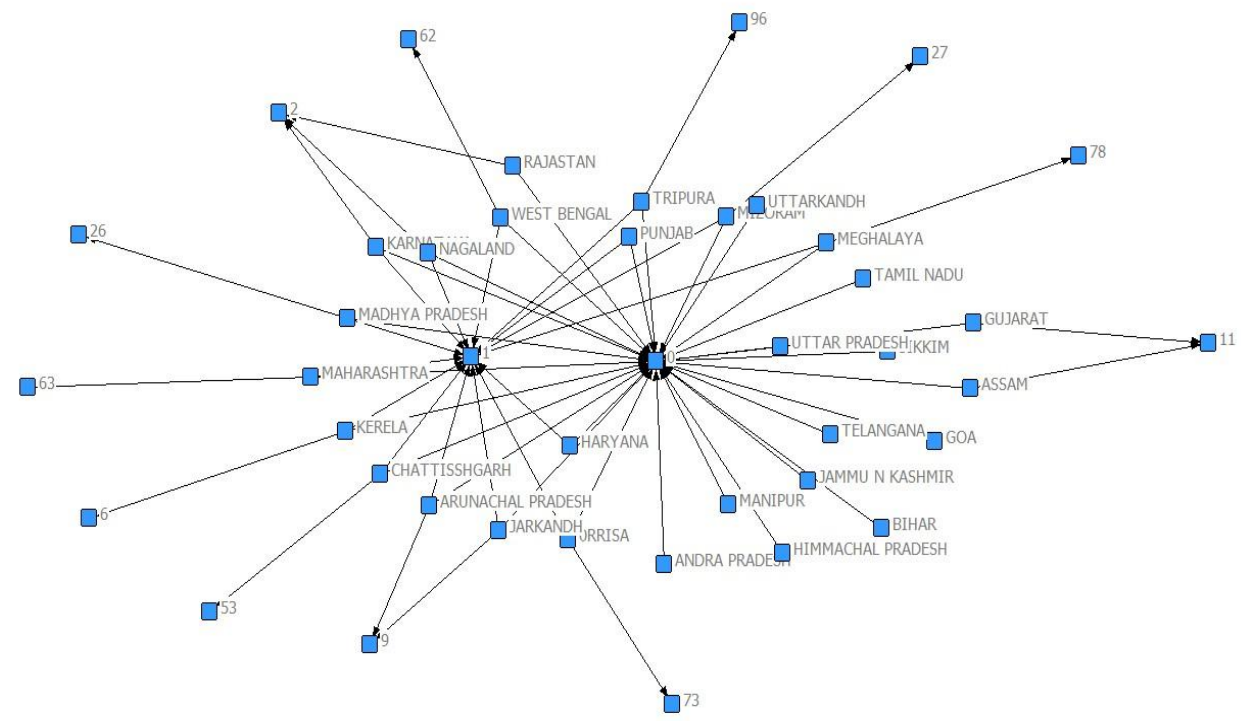

Fig 4: States Affected By Malaria 
The network diagram given below shows the states through which the disease gets transmitted.
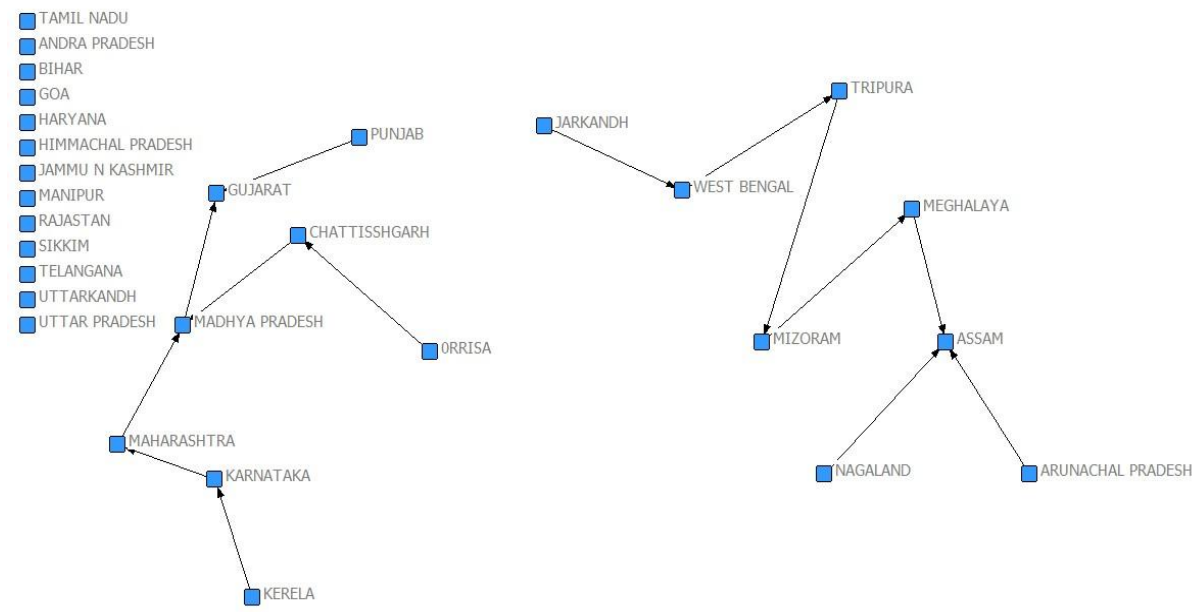

Fig 5 : States Through Which The Disease Gets Transmitted

\section{BETWEENESS CENTRALITY MEASURE}

The betweeness centrality is a measure of centrality in a graph based on shortest paths. For every pair of vertices in a graph, there exists at least a shortest path between the vertices such that either the number of edges that the path passes through (for un-weighted graphs) or the sum of the weights of the edges (for weighted graphs) is minimized.

\section{CALCULATING BETWEENESS CENTRALITY USING UCINET}

\section{2}

Betweenness nBetweenness

\begin{tabular}{|c|c|c|c|}
\hline MIZORAM & 6.000 & 0.794 & \\
\hline TRIPURA & 6.000 & 0.794 & \\
\hline MADHYA PRADESH & 5.000 & 0.661 & \\
\hline MEGHALAYA & & 4.000 & 0.529 \\
\hline MAHARASHTRA & 4.000 & 0.529 & \\
\hline WEST BENGAL & 4.000 & 0.529 & \\
\hline KARNATAKA & & 3.000 & 0.397 \\
\hline CHATTISSHGARH & 2.000 & 0.265 & \\
\hline ARUNACHAL PRADESH & H $\quad 0.000$ & 0.000 & \\
\hline GOA & & 0.000 & 0.000 \\
\hline JAMMU N KASHMIR & & 0.000 & 0.000 \\
\hline HARYANA & 0.000 & 0.000 & \\
\hline HIMMACHAL PRADESH & H $\quad 0.000$ & 0.000 & \\
\hline KERELA & 0.000 & 0.000 & \\
\hline GUJARAT & 0.000 & 0.000 & \\
\hline ANDRA PRADESH & 0.000 & 0.000 & \\
\hline MANIPUR & 0.000 & 0.000 & \\
\hline ASSAM & & 0.000 & 0.000 \\
\hline BIHAR & & 0.000 & 0.000 \\
\hline NAGALAND & & 0.000 & 0.000 \\
\hline ORRISA & & 0.000 & 0.000 \\
\hline PUNJAB & 0.000 & 0.000 & \\
\hline RAJASTAN & 0.000 & 0.000 & \\
\hline SIKKIM & & 0.000 & 0.000 \\
\hline TELANGANA & 0.000 & 0.000 & \\
\hline JARKANDH & 0.000 & 0.000 & \\
\hline UTTARKANDH & 0.000 & 0.000 & \\
\hline UTTAR PRADESH & 0.000 & 0.000 & \\
\hline TAMIL NADU & & 0.000 & 0.000 \\
\hline
\end{tabular}


DESCRIPTIVE STATISTICS FOR EACH MEASURE

1

Betweenness
2

nBetweenness
1. Mean

2. Std Dev 2.018

3. Sum

4. Variance

5. SSQ

6. MCSSQ 118.138

7. Euc Norm

8. Minimum

9. Maximum

10. $\mathrm{N}$ of Obs

$$
1.172
$$

34.000

4.074

158.000

12.570

0.000

6.000

29.000
0.155

0.267

4.497

0.071

2.764

2.067

1.633

0.000

0.794

29.000

Network Centralization Index $=0.66 \%$

\section{CLOSENESS CENTRALITY MEASURES}

In a connected graph, the closeness centrality (or closeness) of a node is a measure of centrality in a network, calculated as the sum of the length of the shortest paths between the node and all other nodes in the graph. Thus the more central a node is, the closer it is to all other nodes.

\section{CLOSENESS CENTRALITY MEASURES USING UCINET}

$\begin{array}{llllll}1 & 2 & 3 & 4 & 5 & 6\end{array}$

OutCl InClo OutVa InVal OutRe InRec

ose se $1 \mathrm{Clo}$ Clo cipCl ipClo

0.1670 .1670 .0000 .0000 .0000 .000

0.1670 .1670 .0000 .0000 .0000 .000

ANDRA PRADESH

ARUNACHAL PRADESH

ASSAM

BIHAR

CHATTISSHGARH

GOA

GUJARAT

HARYANA

HIMMACHAL PRADESH

JAMMU N KASHMIR

JARKANDH

KARNATAKA

KERELA

MADHYA PRADESH

MAHARASHTRA

MANIPUR

MEGHALAYA

MIZORAM

NAGALAND

ORRISA

PUNJAB

RAJASTAN

SIKKIM

TELANGANA

TRIPURA

UTTARKANDH

UTTAR PRADESH

WEST BENGAL
0.1720 .1670 .0360 .0000 .0360 .000

0.1670 .1960 .0000 .2380 .0000 .153

0.1670 .1670 .0000 .0000 .0000 .000

0.1760 .1720 .0700 .0360 .0540 .036

0.1670 .1670 .0000 .0000 .0000 .000

0.1670 .1970 .0000 .2390 .0000 .140

0.1670 .1670 .0000 .0000 .0000 .000

0.1670 .1670 .0000 .0000 .0000 .000

0.1670 .1670 .0000 .0000 .0000 .000

0.1830 .1670 .1660 .0000 .0820 .000

0.1790 .1720 .1030 .0360 .0650 .036

0.1820 .1670 .1350 .0000 .0740 .000

0.1720 .1900 .0360 .1740 .0360 .119

0.1760 .1760 .0700 .0700 .0540 .054

0.1670 .1670 .0000 .0000 .0000 .000

0.1720 .1820 .0360 .1350 .0360 .074

0.1760 .1790 .0700 .1030 .0540 .065

0.1720 .1670 .0360 .0000 .0360 .000

0.1790 .1670 .1030 .0000 .0650 .000

0.1720 .1670 .0360 .0000 .0360 .000

0.1670 .1670 .0000 .0000 .0000 .000

0.1670 .1670 .0000 .0000 .0000 .000

0.1670 .1670 .0000 .0000 .0000 .000

0.1790 .1760 .1030 .0700 .0650 .054

0.1670 .1670 .0000 .0000 .0000 .000

0.1670 .1670 .0000 .0000 .0000 .000

0.1820 .1720 .1350 .0360 .0740 .036 


\section{CONCLUSION}

These studies were conducted on the appreciation of remote sensing and GIS applications to the study of vector's biodiversity, vector presence, vector abundance and the vector-borne diseases with respect to space and time. And to map the vector breeding potential areas vulnerable to risk of disease transmission and could be provided the possible information on reliable estimates of and mapping of malaria, filariasis, JE, and dengue vector breeding habitats, and facilitate to estimate the people at risk by creating network diagram using ucinet and also finding the closeness and betweeness centrality measures of disease transmitting in each state of India.

\section{ACKNOWLEDGEMENT}

This project has been supported by UCINET

\section{REFERENCES}

[1] Amerasinghe FP. "Irrigation and mosquito-borne diseases", Journal of Parasitology, 89:14-22, 2003.

[2] Beck LR, Rodriguez MH, Dister SW, Rodriguez AD, Washino RK, Roberts DR et al. “Assessment of a remote sensing-based model for predicting malaria transmission risk in villages of Chiapas Mexico”,Am J Trop Med \& Hyg; 56:99-106, 1997.

[3] Bhattacharya S, Sharma C, Dhiman RC, Mitra AP, " Climate change and malaria in India. Current Science”, 90(3):369-375, 2006.

[4] Baret F, Guyot G," Potentials and limits of vegetation indices for LAI and APAR assessment", Remote Sens. Environ,35:161-173,1991.

[5] Bavia ME, Carneiro DD, Hda CG, Filho CM, Barbosa MG," Remote Sensing and Geographic Information Systems and risk of American visceral leishmaniasis in Bahia, Brazil”, Parassitologia, 47(1):165-169, 2005.

[6] Dale PE, Morris CD, "Culex annulirostris breeding sites in urban areas: using remote sensing and digital image analysis to develop a rapid predictor of potential breeding areas”,J Am Mosq Control Assoc; 12:316-320,1996

[7] R Vidhya, G Vadivu, Research Document Search using Elastic Search, Indian Journal of Science and Technology 9 (37), 2016.

[8] T. Y. J. Naga Malleswari, G. Vadivu, "Map reduce: A Technical Review”, Indian Journal of Science and Technology, Vol 9(1), January 2016.

[9] K.Sornalakshmi, G.Vadivu, “A Survey on Realtime Analytics Framework for Smart Grid Energy Management”, International Journal of Innovative Research in Science, Engineering and Technology, March 2015.

[10] Dale PE, Ritchie SA, Territo BM, Morris CD, Muhar A, Kay BH et al. "An overview of remote sensing and GIS for surveillance of mosquito vector habitats and risk assessment", J Vector Ecol; 23:54-61,1998.

[11] Gilruth D, Rogers, Szczur M. "Surveillance of arthropod vector-borne infectious diseases using remote sensing techniques: a review",PLoS Pathog; 3(10):1361-1371, 2007.

[12] Gleiser RM, Gorla DE, Almeida FFL. "Monitoring the abundance of Aedes (Ochlerotatus) albifasciatus (Macquart 1838) (Diptera: Culicidae) to the south of Mar Chiquita Lake, central Argentina, with the aid of remote sensing”. Ann of Trop Med and Parasit; 91:917-926,1997.

[13] Hales S, Woodward A.” Climate change will increase demands on malaria control in Africa”. Lancet,362:1775, 2003.

[14] Navin, G. Vadivu, "Big Data Analytics for Gold Price Forecasting Based on Decision Tree Algorithm and Support Vector Regression (SVR)", International Journal of Science and Research (IJSR), March 2015.

[15] G.Vadivu, Waheeta Hopper, "Ontology Mapping of Indian Medicinal Plants with Standardized Medical Terms", Journal of Computer Science, ISSN 1549-3636., Aug, 2012. 